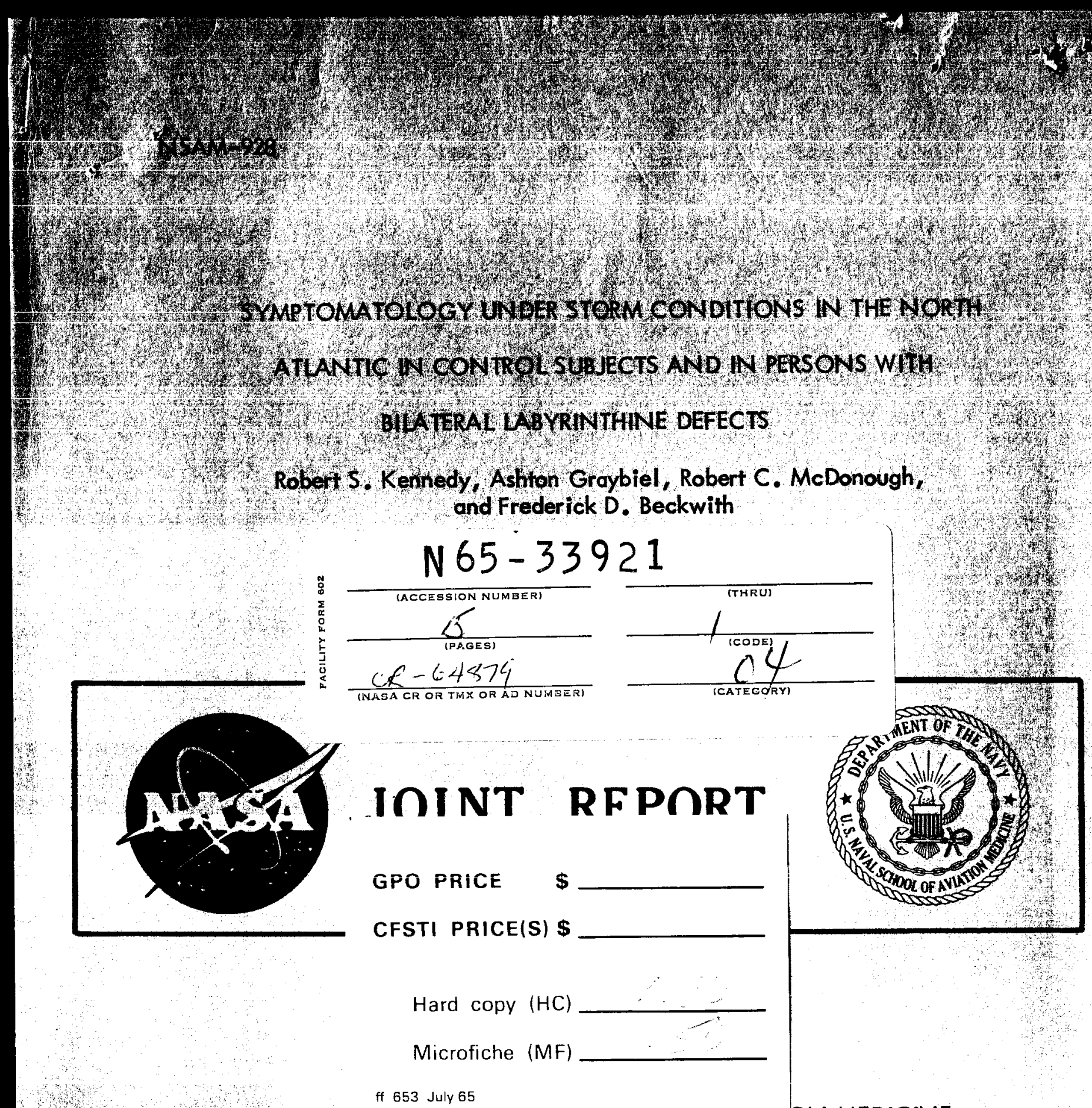

UNITEU SIAIES NAVAL SCHOUL OF AVIATION MEDICINE

NATIONAL AERONAUTIĆS ÁND SPAACE ÁḊMiN ISTTKÁTIÓN

May 1965

Distribution of this document is unlimited. 
Distribution of this document is unlimited.

\title{
SYMPTOMATOLOGY UNDER STORM CONDITIONS IN THE NORTH ATLANTIC IN CONTROL SUBJECTS AND IN PERSONS WITH \\ BILATERAL LABYRINTHINE DEFECTS*
}
Robert S. Kennedy, Ashton Graybiel, Robert C. McDonough, and Frederick D. Beckwith

\author{
Bureau of Medicine and Surgery \\ Project MR005.13-6001 \\ Subtask 1 Report No. 112 \\ NASA Order No. R-93
}

\author{
Released by \\ Captain H. C. Hunley, MC USN \\ Commanding Officer
}

* This research was conducted under the sponsorship of the Office of Life Science Programs, National Aeronautics and Space Administration. 


\section{SUMMARY PAGE}

THE PROBLEM

To determine if labyrinthine defective subjects ( $L-D$ 's) could be made seasick under severe weather conditions and to determine the comparative effects in normal subjects of whom many were highly resistant to motion sickness under various force environments.

\section{FINDINGS}

Ten L-D and twenty normal subjects sailed from North Sydney, Nova Scotia, to St. Pierre and return, the latter trip being made under extremely severe weather conditions. None of the L-D subjects manif ested typical symptoms of motion sickness; one reported "gas in the stomach" and another "constriction in the throat and slight nausea--cerebral not gastrointestinal." Fifteen of the twenty normals vomited and five experienced severe or moderate malaise. All of the L-D subjects reported discomfort due to the physical conditions, and some were afraid. This fear bordered almost on panic in several of the normals, contributing to the stress, and was the origin of some of their symptoms.

Were it possible for motion sickness symptoms to be precipitated by fear, then the L-D subjects surely would have become sick. The fact that they did not suggests that, even in instances where motion sickness symptoms appear to be triggered by anxiety, the vestibular organs play an essential etiological role.

\section{ACKNOWLEDGMENTS}

Many persons of good will participated in this experiment. Special acknowledgment is due to all of the subjects, some of whom served as assistants, and to the Captain and crew of the MS MIQUELON. 


\section{INTRODUCTION}

That many deaf persons are unsusceptible to motion sickness has been known since at least the time of James (1). Later work by Sjöberg (2) suggested that lack of labyrinthine function was responsible for resistance to seasickness and not a history of deafness per se. Siöberg's study was in two parts: 1) Three young females who were selected out of thirty deaf persons failed to become sick when hoisted up and down by means of a crane, and 2) four dogs who previously became sick in the crane did not do so after bilateral labyrinthectomy. Recent attempts have been made to extend Sjöberg's studies by exposing larger groups of vestibular defective individuals to unusual force environments. In these studies normal males and labyrinthine defectives (L-D's) were subjected to: acrobatics in aircraft $(3,4)$, head movements in the Pensacola Slow Rotation Room (5), changing linear forces in a counter rotating room (6), and weightlessness induced by flying Keplerian trajectories (7). None of the L-D subjects reported symptoms which were characteristic of motion sickness in any of the above circumstances. On the other hand, typical symptoms of motion sickness were observed in all of the control subjects in one or more of these force environments.

The present study was undertaken partly to determine if $L-D$ subjects could be made seasick under severe weather conditions and partly to determine the comparative effects in normal subjects, many of whom were highly resistant to motion sickness under the conditions mentioned above.

\section{PROCEDURE}

\section{THE SHIP}

The ship used in this experiment (Figure 1) was the MS MICHELON (French), a round bottomed, wooden, sea-going tug, and former U. S. Army transport. It was short $\left(145^{\prime}\right)$, narrow ( $33^{\prime}$ abeam), light(546 tons), shallow draft $\left(15^{\prime} 6^{\prime \prime}\right)$, and lacked stabilization gear. When underway, these unusual dimensions occasioned a great deal of roll, but the ship was seaworthy.*

\section{SUBJECTS}

Twenty controls and ten labyrinthine defective (L-S) subjects comprised the experimental group. All were males in good health. The positive function of the vestibular apparatus was assessed by five tests: i) threshoid caioric (8), 2) counierroliing $(7)$, 3) a new quantitative ataxia test battery (10), 4) Slow Rotation Room (SRR) performance (11), and 5) a Motion Sickness Questionnaire (MSQ) (12).

- - ...-...- -

*As testimony to its being seaworthy: For several years it has been used as a year-round ferry and supply ship between North Sydney, Nova Scotia, and St. Pierre/Michelon, a French possession in the North Atlantic off the coast of Newfoundland. Heavy seas are routine during the winter months, and on some crossings even the ship's crew have reported seasickness. 


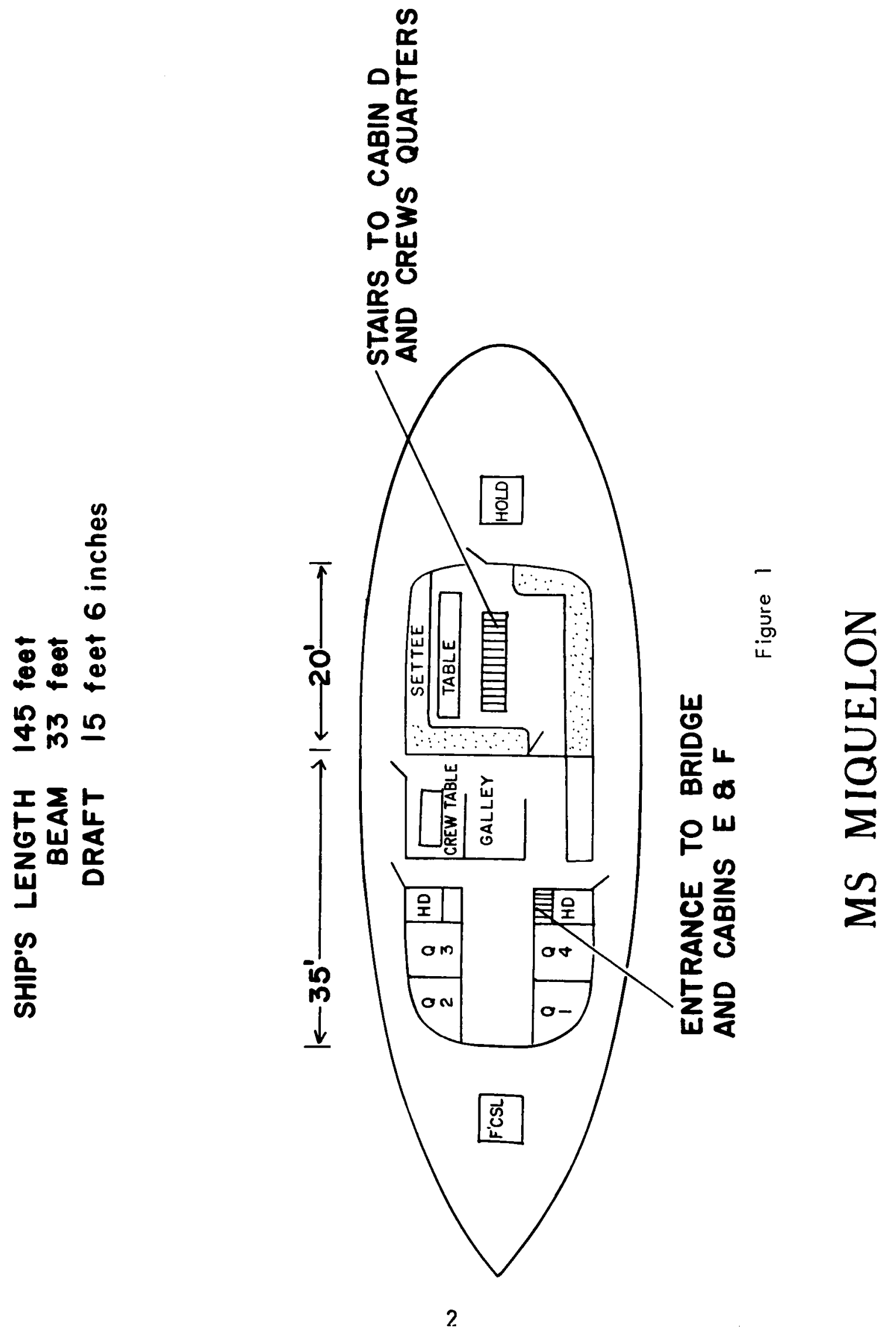


1) Threshold Caloric--All the control subjects manifested a clear-cut nystagmic response above $34.4^{\circ} \mathrm{C}$, all but two of them above $35.5^{\circ} \mathrm{C}$. In the L-D subjects there was evidence of a nystagmic response in some instances to prolonged irrigation of the ear with water at or below $10^{\circ} \mathrm{C}$, but its significance in terms of vestibular function was doubtful; in any event, it is altogether likely that no useful canal function remained in any of these subjects.

2) Counterrolling--The counterrolling index (13) was normal in the control subjects. Two of the L-D subjects manifested slight (far less than normal) roll, and it was negligible in the remainder.

3) Ataxia Test--The performance of the controls was far better than that of the L-D's(before practice, ref. 10), with one exception. The one exception was subject ZA who obtained a 50th percentile score on one portion of this test (Walking eyes open), and he has had much experience in ballet. All other $L-D$ scores on all the other subtests were in the first percentile.

4) Slow Rotation Room--All the subjects were exposed to a standardized procedure, the Dial Test (14), aboard the SRR. The subjects rotated at 7.5 RPM and if symptom free at the conclusion of 100 dial settings, the speed was increased to 10 RPM and then similarly to $20 \mathrm{RPM}$. Some of the subjects terminated their exposure at either $7.5,10$, or 20 RPM, and three control subjects completed 20 RPM with only very minor symptoms. All the L-D's executed their test through 20 RPM and without symptoms of motion sickness.

5) Motion Sickness Questionnaire--The past histories of motion sickness in the control group presented a range of susceptibility. Nine of the control subjects were considerad highly resistant to motion sickness because the ir backgrounds gave evidence of many occasions in which they might have experienced motion sickness and did not do so. Two were senior flight surgeons (BE, MC); two were retired Navy enlisted men (UP, $T R$ ); one was the research pilot (CA) who normally flies the airsickness profiles (i.e., acrobatics) in a research aircraft; three were regular volunteer laboratory research subjects (DE, VA, JD), and one was an experimenter (KE) from Slow Rotation Room studies; the other eleven members of the control group were of varying susceptibilities. Of the ten L-D's only two reported a past history of motion sickness. In each case these were single incidents which occurred in childhood and probably before meningitis had developed.

Results of Clinical Findings

The results of the findings from these five measures indicated that, while a normal range of vestibular function was man ifested in the control group, this function was either absent or of no practical significance in the L-D group. The susceptibility to motion sickness was $\mathrm{nil}$ in the L-D subjects while: the controls as a group were less susceptible than the average. 
The experimental plan was to board the ship in Nova Scotia for a 200-mile trip to the island of St. Pierre, requiring about eighteen hours, after which a rest period was planned, and the group was to await calm or rough weather for the return trip, depending on the sea state encountered on the first crossing.* In addition to the assessment of motion sickness symptomatology, plans were made to measure biochemical changes, postural equilibrium, and egocentric visual localization of the horizontal. These findings will appear in separate reports. Measurement of cardiovascular changes (specifically orthostatic hypotension) were intended but were not done because the experimenters became incapacitated. The linear and angular accelerations of the craft were also to be measured at certain intervals, and these experimenters too became incapacitated.

Motion sickness symptomatology was scored after the method of Graybiel (15) and the major vestibular symptoms used in this diagnostic categorization are included in Table I (from ref. 15).

During the two voyages, all subjects remained mainly in the salon, aft, or central cabin area, amidships. Both areas were approximately equidistant from the center of gravity, and a similar acceleration environment existed in both.

The first crossing from Nova Scotia to St. Pierre was uneventful. The sea was calm, and the ship's Captain claimed that, considering the time of year, the trip was one of the smoothest he had experienced. Very mild symptoms of motion sickness were reported by only a few men and these rapidly (< two hours) subsided. Since the first trip proved uneventful for experimental purposes, it was decided to await rough weather for the return voyage to the mainland.

On the afternoon of the fifth day ashore a storm moved by, and the experimental group boarded the ship that evening. Because of the darkness, external visual reference aboard ship was nil. The ship cleared the harbor at 2100, and the sea condition was very rough. Waves were estimated at 40 feet, and these produced an estimated roll of $40+$ degrees. The Captain was requested to rate the sea-state on a ten-point scale using the first trip as 1 (the mildest) and to consider 10 the most severe in his experience. This trip was assigned 7. Winds of 40 knots (gusts to 80 knots) were encountered for most of the first eight hours underway, after which the weather subsided. Acceleration recordings taken (not necessarily at the height of the storm) showed scend of $>3 G$ and roll rate of $>10$ degrees per second. The entire trip lasted twenty-eight hours, which was half again as long as the first trip. A further testimony to the condition of the sea state is the fact that two larger commercial ships sailing through the storm foundered and broke up.

* The attempt was to prove the experimental hypothesis of "100 per cent sick in the control group and zero per cent in the L-D group." 


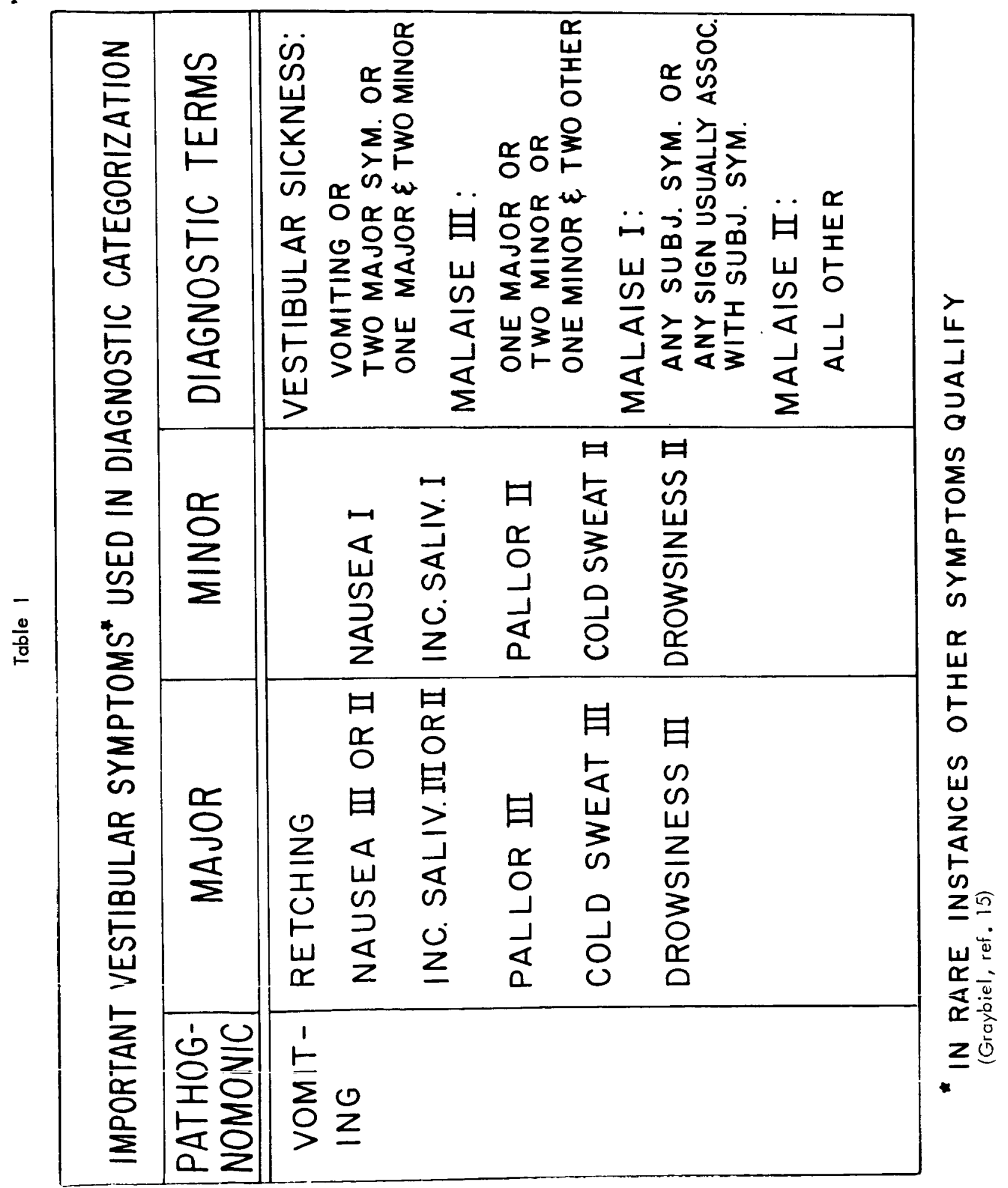


Maximum Symptomatology Experienced by 10 L-D (Alphabetically Listed) and 20 Control ${ }^{\circ}$ Subjects (Ranked by Sickness) During 28 Hours at Sea

\begin{tabular}{llll}
\hline \multicolumn{2}{c}{ Controls } & & \\
Subject & Symptoms & Subject & L-D's \\
\hline SA & Emesis & DO & Symptoms \\
WH & Emesis & GR & Drowsiness* \\
MC & Emesis & GU & Drowsiness \\
DA & Emesis & HA & Throat constriction \\
BE & Emesis & & Slight nausea (see text) \\
UP & Emesis & JO & Drowsiness \\
ST & Emesis & LA & Salivation \\
RI & Emesis & MY & General discomfort \\
TR & Emesis & PE & Drowsiness \\
AL & Emesis & ST & Gas on the stomach \\
TD & Emesis & ZA & Drowsiness \\
CA & Emesis & & \\
KE & Emesis & & \\
TB & Emesis & & \\
PO & Emesis & & \\
OV & Malaise III & & \\
JO & Malaise III & & \\
DO & Malaise III & & \\
VA & Malaise III & & \\
DE & Malaise II & & \\
\hline
\end{tabular}

*Drowsiness was reported by all ten after 0200 .

\section{RESULTS}

Table II categorizes the maximum symptomatology experienced by the control group and the ten L-D subjects. The control group is ranked by time of emesis or degree of "sickness"; fifteen of the twenty in the group vomited, and five experienced severe or moderate malaise. One of the ten L-D subjects reported "gas on the stomach" and another "constriction in the throat." The latter also recorded "slight nausea" on his response form but when questioned later, he claimed it was "cerebral" and not "gastrointestinal." All ten mentioned "general discomfort" due to the physical environment, six also experienced "drowsiness" due to the late hour, and one, salivation while eating. None of these L-D subjects, however, manifested symptoms which were considered to be typical of motion sickness. 
The control subjects' rankings were compared with ratings of performance in the SRR and responses on the MSQ. The rating scale employed classified the subjects as: 1) far more susceptible than average, 2) more than, 3) average, 4) less than, and 5) far less susceptible than average. The correlation coefficients for these variables appear as Table III and all are statistically significant.

Table III

Correlations Among SRR Performance, MSQ Responses, and Seasickness for Twenty Control Subjects

1. Seasick rank and SRR performance

2. Seasick rank and $M S Q$ response

3. SRR performance and $M S Q$ response

$$
\begin{aligned}
& r=.829 * \\
& r=.533 * \\
& r=.690 *
\end{aligned}
$$

*For $N=20$ an $\underline{r}$ of .537 is significant at the .01 level.

\section{DISCUSSION}

The results of this experiment are clear-cut. None of the L-D subjects exhibited characteristic symptoms of seasickness whereas all the control subjects did. Over 70 per cent of the controls vomited and the rest qualified for Malaise III or II (cf. Table I). All of the L-D subjects reported discomfort from the physical environment, and some reported that they were afraid. On the other hand, many of the control subjects who expressed fear did not begin to record these fears in their diaries until after their seasickness symptoms subsided. This seems particularly noteworthy with respect to the psychogenic cause of motion sickness, since the L-D subjects were extremely anxious throughout the first evening and none vomited. Indeed they would not go to sleep, but secured themselves to chairs in the salon and tried to play cards. It is felt that were it possible for motion sickness symptoms to be precipitated by fear such as some experienced, then they surely would have become sick. However, the fact that they did not become sick suggests, if it does not prove, that even in other instances where motion sickness symptoms appear to be triggered by anxiety the vestibular organs piay an essentiai etiological role. Stated differently, anxiety may modulate the severity of motion sickness symptoms, but inasmuch as the relative contribution of the ir influence upon the control subject's performance is unknown, in the absence of verif iabie vegarative reaciionis in the L-D subjects it is suggested that the vestibular stimulus was the major contributing component. 
As the sea condition became less violent, vomiting episodes were less frequent, and by the time the ship docked after twenty-eight hours at sea, most of the control subjects (but not all) had fully recovered.

The high correlations which were obtained between the pretests of susceptibility (SRR and MSQ) and the time or degree of seasickness indicate that a general factor exists and demonstrates the need for adequate evaluation and selection of subjects prior to the ir exposure to experimental conditions. For example, the effects of drugs, temperature, or various force environments or any experiment where few subjects are utilized or the same subjects are used more than once could be influenced by these factors.

In summary it is felt that: 1) If these L-D subjects are representative of the population from which they were drawn (and there is no reason to suspect they are not), then vestibular function is a necessary requirement for the experience of motion sickness symptoms under seagoing conditions; 2) susceptibility as observed in a very rough sea condition is highly correlated with a laboratory technique for producing canal sickness and with a past history of motion sickness. 


\section{REFERENCES}

1. James, W., The sense of dizziness in deaf mutes. Amer. J. Otol., 4:239-254, 1882 .

2. Sjobërg, A., Experimentelle Studien über den Auslösungmechanismus der Seekrankheit. Acta otolaryng., Stockh., Suppl. 14, 1-136, 1931.

3. Kennedy, R. S., and Graybiel, A., Validity of tests of canal sickness in predicting susceptibility to airsickness and seasickness. Aerospace Med., 33:935-938, 1962.

4. Colehour, J. K., and Graybiel, A., Excretion of 17-hydrocorticosteroids, catechol amines, and uropepsin in the urine of normal persons and deaf subjects with bilateral vestibular defects following acrobatic flight stress. Aerospace Med., 35:370-373, 1964.

5. Graybiel, A., Clark, B., and Zarriello, J. J., Observations on human subjects living in a "slow rotation room" for periods of two days. Arch. Neurol., 3: $55-73,1960$.

6. Graybiel, A., and Johnson, W. H., A comparison of the symptomatology experienced by healthy persons and subjects with loss of labyrinthine function when exposed to unusual patterns of centripetal force in a counter-rotating room. Ann. Otol. , 72:357-373, 1963.

7. Kellogg, R. S., Kennedy, R. S., and Graybiel, A., Motion sickness symptomatology of labyrinthine defective and normal subjects during zero gravity maneuvers. Aerospace Med., 36:315-318, 1965.

8. McLeod, M. E., and Meek, J. C., A threshold caloric test for the horizontal semicircular canal. NSAM-834. NASA Order No. R-47. Pensacola, Fla.: Naval School of Aviation Medicine, 1962.

9. Miller, E. F., II, Counterrolling of the human eyes produced by head tilt with respect to gravity. Acta otolaryng., Stockh., 54:479-501, 1961 .

10. Graybiel, A., and Fregly, A. R., A new quantitative ataxia test battery. NSAM919. NASA Order No. R-93. Pensacola, Fla.: Naval School of Aviation Medicine, 1965.

11. Clark, B., and Graybiel, A., Human performance during adaptation to stress in the Pensacola Slow Rotation Room. Aerospace Med., 32:93-106, 1961. 
12. Hardacre, L. E., and Kennedy, R. S., Some issues in the development of a motion sickness questionnaire for flight students. Aerospace Med., 34:401$402,1963$.

13. Miller, E. F., II, and Graybiel, A., A comparison of ocular and counterrolling movements between normal persons and deaf subjects with bilateral labyrinthine defects. Ann. Otol., 72:885-893, 1963.

14. Kennedy, R. S., and Graybiel, A., The Dial Test: A standardized procedure for the experimental production of canal sickness symptomatology in a rotating environment. NSAM-930. NASA Order No. R-93. Pensacola, Fla.: Naval School of Aviation Medicine, 1965.

15. Graybiel, A., Vestibular sickness and some of its implications for space flight. In: Fields, W. S., and Alford, B. R. (Eds.), Neurological Aspects of Auditory and Vestibular Sickness. Springfield, III.: Charles C Thomas, 1964. 
Unclassified

Security Classification

DOCUMENT CONTROL DATA - R\&D

(Socurity clessification of tille, body of abstrace and indexing annotation must be entered when the overall report is classified)

1. ORIGINATING ACTIVITY (Comorate author)

U.S. Naval School of Aviation Medicine

Pensacola, Florida UNCLASS IFIED

$2 b$ GROUP

3. REPORT TITLE

Symptomatology Under Storm Conditions in the North Atlantic in Control Subjects

and in Persons with Bilateral Labyrinthine Defects

4. DESCRIPTIVE NOTES (Type of report and inclusive datos)

5. AUTHOR(S) (Last name, firs t name, initial)

Kennedy, Robert S., Graybiel, Ashton, McDonough, Robert C., and Beckwith,

Frederick D.

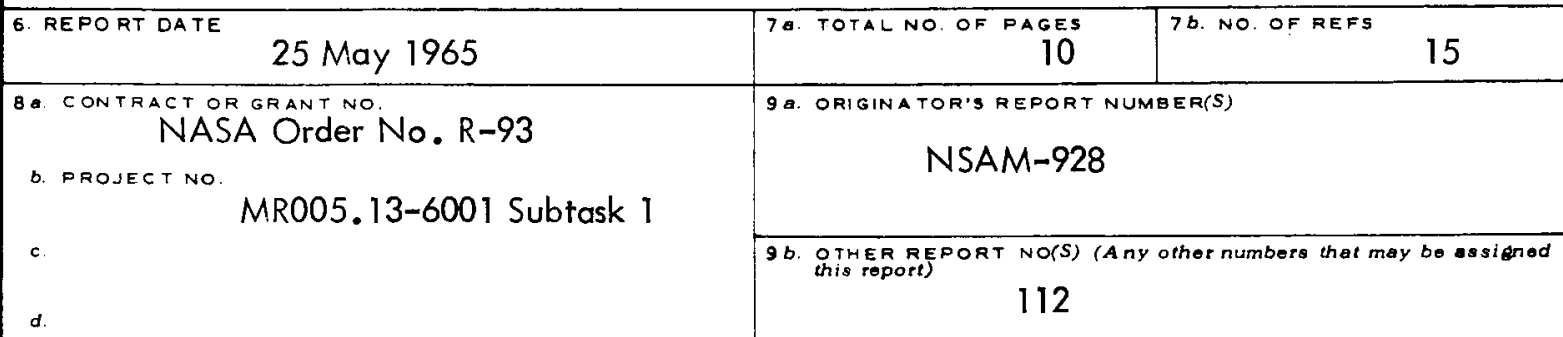

10 AVAILABILITY/LIMITATION NOTICES Qualified requesters may obtain copies of this report from DDC. Available for sale to the public, from Federal Clearinghouse for Scientific and Technical Information, Springfield, Virginia.

\begin{tabular}{|l|l}
\hline 11. SUPPLEMENTARY NOTES & 12. SPONSORING MILITARY ACTIVITY
\end{tabular}

13. ABSTRACT

Ten labyrinthine defective ( $L-D)$ and twenty normal subjects were exposed to extremely severe weather conditions during a sea voyage. The effects of such a stress were complicated by a feeling of fear in all of the normal and in some of the L-D subjects. None of the latter manifested typical symptoms of motion sickness whereas all of the normal subjects did. The fact that the L-D subjects did not become sick suggests that, even in instances where motion sickness symptoms appear to be triggered by anxiety, the vestibular organs plan an essential etiological role. 


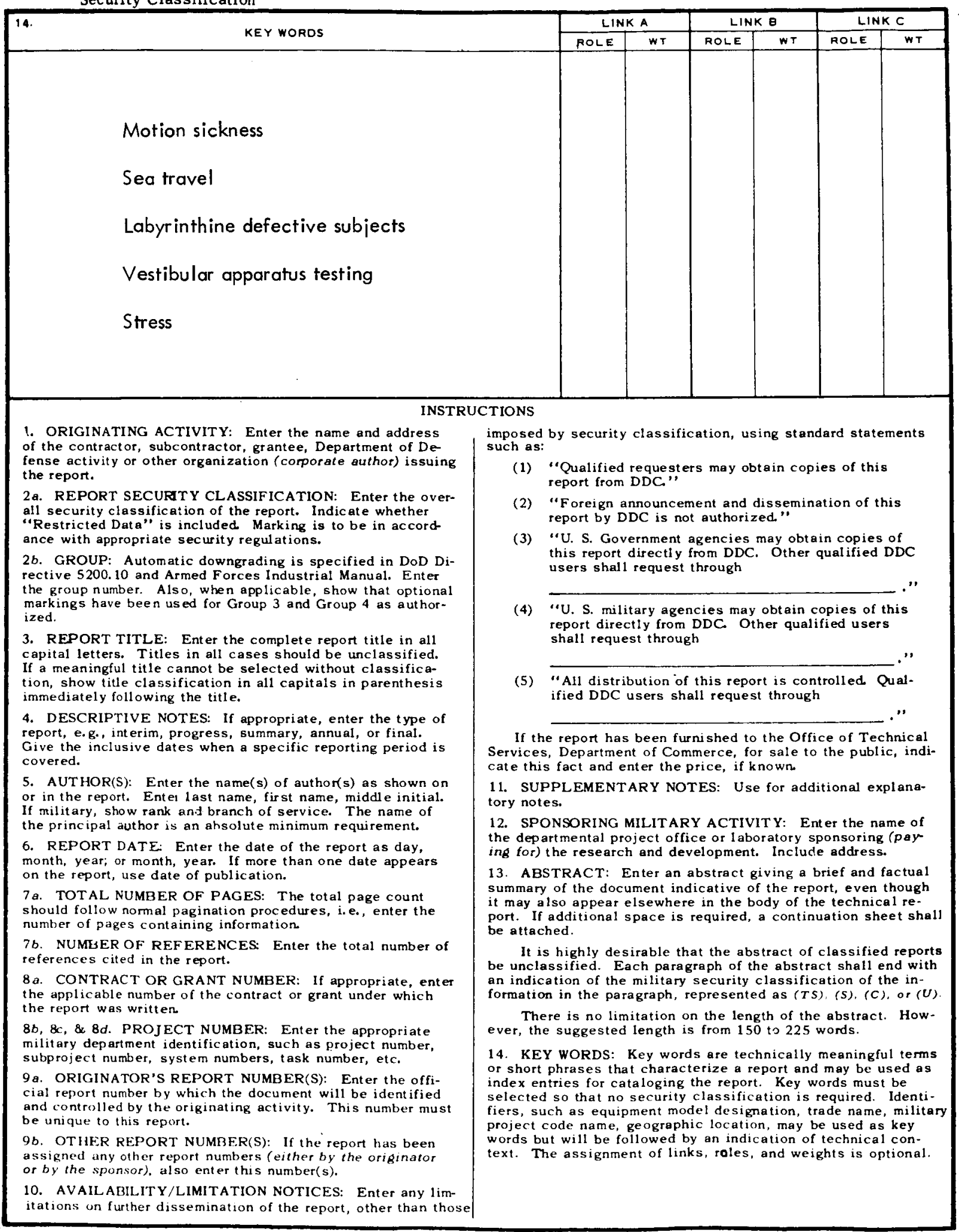

